\title{
As lutas hegemônicas nos saques em Abreu e Lima (PE) em 2014
}

\author{
The hegemonic struggles involving the looting in Abreu e \\ Lima (PE) in 2014
}

Guilherme Figueredo Benzaquen*

\section{RESUMO}

Em 2014, aconteceu uma greve da Polícia Militar pernambucana, em cujo período se destacam os saques em Abreu e Lima. A cidade nunca tinha vivido algo similar e seus moradores se impressionaram com a forma como os saques se deram. Após o evento, houve uma série de articulações com o intuito de reconstituição de um "apropriado" no contexto local. Entendendo esse processo como lutas hegemônicas a partir de teorias pós-marxistas, é objetivo central deste artigo analisar as mobilizações e ações coletivas que ocorreram durante e após os saques, explorando seu caráter político e suas articulações e equivalências. A pesquisa realizada incluiu trabalho de campo, com entrevistas semiestruturadas, e análise de jornais e vídeos. Assim, o artigo expõe aspectos relevantes dessa suspensão relativa do cotidiano e da disputa posterior em torno da reconstituição da hegemonia na cidade. ${ }^{\diamond}$

Palavras-chaves: saque, hegemonia, pós-marxismo.

\footnotetext{
* Universidade Federal de Pernambuco, Recife, PE, Brasil.

Pós doutorando no Programa de Pós-Graduação em Sociologia da Universidade Federal de Pernambuco (PPGS/UFPE). Email: benzaquenguilherme@gmail.com

$\checkmark$ Gostaria de agradecer a Remo Mutzenberg pelos diálogos durante a pesquisa e a Sophia Branco pelos comentários feitos a uma versão anterior deste texto. Agradeço também aos pareceristas e à equipe editorial da Revista Brasileira de Sociologia que contribuíram com a melhora do texto. Assumo, no entanto, a responsabilidade pelas possíveis incorreções que ainda permanecem.
} 


\begin{abstract}
In 2014, the Military Police of the state of Pernambuco went on strike. During such period, a series of lootings took place in Abreu e Lima. The town had never experienced anything similar and its residents were impressed by the way the lootings were carried out. After the event, there were articulations to reconstruct an "appropriate" in the local context. Understanding this process in the context of hegemonic struggles, the main objective of this article is to analyze the collective actions that occurred during and after the lootings, exploring their political character and their articulations and equivalences. The research was carried out with a fieldwork, semi-structured interviews and the analysis of newspapers and videos. The article exposes relevant aspects of this relative suspension of daily life and the subsequent dispute over the reconstitution of hegemony in the town.
\end{abstract}

Keywords: looting, hegemony, post-marxism.

\title{
Introdução
}

O objetivo principal deste artigo é analisar as mobilizações e ações coletivas que ocorreram durante e após os saques em Abreu e Lima, Pernambuco, entre os dias 14 e 15 de maio de 2014. Esse foi um processo bastante impactante e, passados alguns anos, sua ocorrência e suas reverberações ainda influenciam as relações e as identidades locais. Entretanto, será aqui demonstrado que a relevância do caso não é meramente local, pois, de acordo com o enfoque teórico-metodológico proposto, ele nos permite analisar aspectos significativos da crise de uma formação hegemônica e de sua reconstituição. O acontecimento será, portanto, compreendido no contexto de lutas hegemônicas, o que significa que será explorado seu caráter político e seus processos de articulação e equivalência. Serão analisados de forma mais detida os saques e as iniciativas de moradores abreu-limenses que ocorreram após o evento - em especial, uma campanha de “conscientização” realizada por um grupo juvenil religioso e um ato organizado por diversos sujeitos da sociedade civil em busca de "recuperar a imagem da cidade". Buscase demonstrar que o momento posterior se desenvolveu com processos de 
articulação na luta hegemônica pela restituição de um "apropriado" frente a um momento de suspensão relativa do cotidiano da cidade.

O referencial teórico adotado para realizar a análise é a teoria pósmarxista, priorizando os conceitos de articulação e hegemonia formulados por Ernesto Laclau e Chantal Mouffe (2001). Esse aparato conceitual se mostrou relevante por desvelar a constituição de identidades coletivas através de processos contingentes de estabelecimento de equivalências entre demandas. Veremos, entretanto, que, para além dessa teoria, se fez necessário recorrer ao complemento crítico desenvolvido recentemente por Mark Devenney $(2011,2020)$. Suas formulações demonstram a importância de enfatizar a discussão acerca da propriedade e do apropriado para a compreensão das lutas hegemônicas.

A análise foi realizada com a construção de uma ampla variedade de dados, sendo uma parte dos resultados de uma pesquisa de doutorado com duração de quatro anos (Benzaquen, 2020). Os principais dados utilizados foram: análise de jornais e de vídeos, assim como um trabalho de campo com dez entrevistas semiestruturadas. Foi feita uma análise documental dos três principais jornais impressos em circulação no estado (Diario de Pernambuco, Folha de Pernambuco e Jornal do Commercio) e de dois sites (G1 e Abreu e Lima em Destaque). Além disso, foi realizada uma análise de 91 vídeos veiculados no Youtube e em sites jornalísticos. ${ }^{1} \mathrm{O}$ trabalho de campo durou cerca de um ano, entre 2017 e 2018, e resultou em dez entrevistas semiestruturadas e trocas informais com abreu-limenses participantes dos acontecimentos investigados. ${ }^{2}$ Esse corpus heterogêneo foi analisado através de triangulações (Flick, 2009) que permitiram a construção da narrativa do evento. Nesse procedimento, uma mesma questão de pesquisa foi constituída a partir de, pelo menos, dois tipos distintos de dados. Dessa maneira, os dados tinham o objetivo de fornecer parâmetros diferentes para a análise,

\footnotetext{
${ }^{1}$ Os materiais coletados nos jornais impressos e sites a serem analisados foram selecionados de acordo com as datas dos acontecimentos. Por seu impacto na dinâmica regional, as notícias não estiveram restritas a cadernos específicos, o que demandou uma cobertura ampla do veiculado nos dias dos saques e nas semanas posteriores. Já os vídeos foram coletados por meio de pesquisas de palavras-chave, que geralmente abarcaram combinações entre "saques", "Abreu e Lima”, "Pernambuco", "greve" e "Polícia Militar". Todos os vídeos relacionados ao acontecimento foram devidamente analisados.

${ }^{2}$ Os interlocutores foram selecionados de acordo com um critério fundamental: a moradia na cidade e a presença no local durante o momento dos saques - ainda que muitos tenham afirmado terem sido apenas espectadores ou estarem dentro de suas casas. Como era de se esperar em um evento passível de criminalização, houve muitas recusas e dificuldades nas tentativas de contato. Essas dificuldades foram superadas com o prolongamento da duração do trabalho de campo e com a utilização da técnica "bola de neve" para facilitar o acesso aos entrevistados.
} 
sabendo-se que mostrariam construções distintas acerca do fenômeno, que foram, ao fim, cotejadas e conjugadas.

A primeira seção do artigo é dedicada à apresentação dos principais conceitos da teoria pós-marxista mobilizados ao longo da análise. Na seção seguinte é analisado o momento específico dos saques. E, na terceira e última parte, serão expostos processos relevantes da restituição hegemônica na cidade. Nas considerações finais, reforça-se a defesa do enfoque político dos saques.

\section{Articulação e hegemonia para o pós-marxismo}

Alguns pontos da teoria pós-marxista devem ser esclarecidos para a compreensão dos saques e das iniciativas posteriores como uma luta hegemônica. Comecemos pela noção de prática articulatória, que é formulada por Laclau e Mouffe (2001, p. 113) da seguinte maneira: "a construção de pontos nodais que fixam parcialmente o significado”. Essa definição é um tanto enigmática para os que não estão familiarizados com os termos utilizados pelos autores, porém é possível torná-la compreensível com alguns breves esclarecimentos. Iniciemos por uma questão central que compõe a definição: o significado. Eles entendem que toda configuração social é significativa, portanto, tudo é discursivo e o discurso não se restringe ao linguístico, pois engloba também o não-linguístico. Tudo que é social tem significado e todo sentido é, nessa concepção, contingente, parcial e localizado. Dessa maneira, o discurso é o território da constituição da objetividade e o “objetivo” é compreendido como uma relação.

Por considerarem as estruturas sociais como sistemas significativos de práticas, Laclau e Mouffe acentuam o papel das práticas articulatórias na estruturação do social porque, sendo essas o momento da fixação parcial do sentido, seriam responsáveis pelo processo constante de conformação do social. Isto é, como tudo tem significado e esses são contingentes e não governados por princípios metafísicos, a articulação é vista como constitutiva do social. Assim, eles utilizam a noção de prática articulatória para lidar com a maneira como os sujeitos constroem identidades e relacionam demandas através da construção de cadeias de equivalências entre elas. Ao se articularem em equivalências, são criados discursos privilegiados que agregam outros em seu entorno. Porém, é preciso atentar que essa constituição é transformadora, ou seja, a articulação sempre altera aquilo 
que é articulado. Isso fica claro em uma outra passagem, na qual os autores propõem outra definição de articulação: “toda prática que estabelece uma relação tal entre os elementos que a identidade dos mesmos é modificada como resultado da própria prática articulatória” (Laclau \& Mouffe, 2001, p. 115). Laclau e Mouffe nos oferecem, portanto, uma teoria da articulação que acentua a contingência e parcialidade das relações sociais, mas que, ao mesmo tempo, a coloca como central para constituição da objetividade.

Dessa maneira, podemos entender que a articulação é uma relação que opera entre identidades e diferenças. Essa operação pode se dar na constituição de uma cadeia de equivalência em torno de pontos nodais que conteriam o "excesso de significados" das muitas diferenças que constituem o social. Em suas palavras, a "equivalência supõe a operação do princípio da analogia entre conteúdos literalmente diversos” (Laclau \& Mouffe, 2001, p. 184). Ela se dá em uma articulação de elementos diferentes centrados em identidades precárias com relação a um externo antagonizado. Lembremos que essa articulação é sempre entendida como limitada, pois não tem uma positividade metafísica dada e delimitada. A constituição de uma relação equivalencial depende da negatividade de um antagonismo e não é necessária porque ela não se fecha num todo predeterminado. "Não há um princípio subjacente fixando - e, portanto, constituindo - o campo das diferenças como um todo" (Laclau \& Mouffe, 2001, p. 185). Assim, as cadeias de equivalência se dão quando as diferenças se redefinem parcialmente por estabelecerem contingencialmente um antagonismo frente a um elemento que não faz parte da cadeia. Constitui-se, dessa maneira, uma oposição das diferenças frente a uma identidade externa com a qual não é estabelecida equivalência - um antagonismo que se coloca como limite e fracasso do fechamento do social.

Estamos no terreno da constituição das hegemonias. ${ }^{3}$ Acerca disso, vejamos como é formulada a atuação dos sujeitos em uma luta

\footnotetext{
${ }^{3}$ Sabe-se que a teoria da hegemonia proposta pelo pós-marxismo é construída a partir do formulado por Gramsci (2002) que utilizava o termo para designar uma liderança de classe - que leva em consideração não só aspectos econômicos, mas também políticos, morais e intelectuais - frente a outras classes e que necessita de algum grau de concessão da classe hegemônica para atender aos interesses das classes subalternizadas. A hegemonia enfatiza os processos ideológicos e políticos de constituição da vontade coletiva na sociedade civil. Porém, para que o conceito de hegemonia fosse reapropriado por Laclau e Mouffe (2001), foi empreendido um trabalho teórico com o intuito de retirar do conceito aquilo que havia de essencialismo e "determinação em última instância" da economia, o que, segundo os pósmarxistas, estava relacionado ao atrelamento da noção de hegemonia ao de uma classe social portadora da essência última da vontade coletiva e a uma compreensão fechada do social na qual a formação social é concebida em torno de um único centro hegemônico.
} 
hegemônica. Os autores argumentam que o social teria uma abertura e uma indecidibilidade constitutivas que estão relacionadas com o fato de que a totalidade é uma impossibilidade, sendo constituída apenas parcialmente a partir da hegemonia: momento em que uma parte se sedimenta contingencialmente como um todo. Assim, como aponta Mutzenberg (2003, p. 43), é a “indecidibilidade’ que abre o campo para a decisão numa ordem da responsabilidade ético-política”. Logo, os processos hegemônicos envolvem tomadas de decisão num terreno de incertezas e estão lidando constantemente com as contingências que apontam para tudo aquilo que escapa. Dessa maneira, a questão do universal só pode ser pensada levando em conta as falhas constitutivas da hegemonia e a sobredeterminação ${ }^{4}$ das distintas demandas concretas que estão constantemente em jogo nos processos políticos que se acumulam no social (Laclau, 1990). Desenvolvendo seu argumento, Laclau afirma que, com essa concepção de hegemonia, não é possível resumir as escolhas políticas a estruturas prévias. O sujeito que toma as decisões não pode ser pensado como separado da estrutura, mas constituído sempre em relação a ela. Assim, as identidades dos sujeitos e da estrutura vão se formando concomitantemente aos processos de atualização do social, ou seja, nos processos políticos de articulação.

Além disso, tenhamos em mente que hegemonizar significa, para Laclau (1990), fixar um sentido em um ponto nodal, ou seja, ocorreria a partir de práticas articulatórias. O social seria uma "guerra de trincheira" em que distintos projetos políticos disputam antagonisticamente para articular em torno de si o máximo de significantes sociais. Porém, como os sentidos são sempre parciais, o social é sempre aberto e há a impossibilidade de uma fixação total, de uma hegemonia completa e inabalável. Fica claro, portanto, o quanto para Laclau (2013) a política é um processo hegemônico e sobredeterminado, pois está relacionado com articulações contingentes e antagônicas. A hegemonia é, então, compreendida como um processo de estabelecimento de equivalências que envolvem a definição fluida de fronteiras antagônicas e a articulação em torno de elementos flutuantes que são ressignificados no processo. Percebemos aqui o esforço pós-

\footnotetext{
${ }^{4}$ Através de uma leitura do desenvolvido por Althusser (2015), Laclau e Mouffe propõem com o conceito de sobredeterminação que a totalidade se apresenta como uma articulação de diferentes práticas e processos que não tem um princípio único que a guiaria teleologicamente. Dessa maneira, a sobredeterminação significa que cada elemento que compõe a totalidade tem determinações próprias, mas é, concomitantemente, sobredeterminado por outras instâncias. Essa é uma forma de analisar o social que busca conciliar o que há de particular em cada processo e o que há nele de interpenetrações de outros processos.
} 
fundacionalista do pós-marxismo que nos alerta constantemente para a parcialidade das identidades e das ações coletivas, criticando as teorias que os concebem através do recurso a um fundamento último e determinante.

Com esse referencial em mente, passemos agora à análise dos saques que ocorreram em Abreu e Lima em 2014.

\section{Os saques durante a greve da Polícia Militar de Pernambuco em 2014}

No dia 13 de maio de 2014 começou a terceira greve da história dos policiais e bombeiros militares de Pernambuco. Suas demandas eram extensas, porém estavam centradas em cinco pontos: reajuste salarial entre 30 e 50\% a depender da patente, reformulação do Plano de Cargos e Carreiras, reestruturação do Hospital da Polícia Militar, mudança do código de disciplina e reajuste do vale-alimentação. Os policiais decretaram greve por tempo indeterminado, depois de uma reunião de negociação malsucedida com representantes do governo. Os soldados foram orientados a se recolher nos quartéis e a não fazer rondas em viaturas nem policiamento a pé ou de moto. Apenas os serviços “essenciais” continuaram funcionando, como o Hospital da Polícia Militar e o cuidado ao armamento. No dia 14, o governo aceitou três demandas: reestruturação do centro médico hospitalar, reformulação do Plano de Cargos e Carreiras e incorporação do risco de vida ao salário-base. Porém, as viaturas policiais continuaram recolhidas nos batalhões. À noite, o Tribunal de Justiça de Pernambuco decretou a ilegalidade da greve após um pedido do governo. Na manhã do dia 15, chegaram 2250 soldados do Exército e das Forças Armadas para auxiliar na segurança com a chamada “Operação Pernambuco”. Na noite do dia 15, depois de 50 horas de seu início, é anunciado o fim da paralisação, mas a decisão salarial ficaria para o ano seguinte.

Durante a greve, a população local viveu momentos que ainda hoje ressoam em suas memórias. O destaque dado nos principais jornais do estado e do país foi ao número de crimes registrados: 234 pessoas foram detidas, suspeitas de furtos, roubos, porte ilegal de arma de fogo, dano qualificado, perturbação do sossego, entre outros crimes. É importante, porém, pontuar que as imagens mais recorrentes daqueles dias são as de grandes saques 
praticados por homens, mulheres, adolescentes, idosos e crianças. Em Abreu e Lima, cidade da Região Metropolitana de Recife (RMR), ${ }^{5}$ muitos estabelecimentos comerciais foram saqueados, o que impressionou bastante a população local. Ao todo, foram 16 horas de saques na cidade mais evangélica do país (IBGE, s.d.), na qual alguns dos moradores entrevistados afirmam se sentir seguros.

Figura 1 - Área de ocorrência dos saques em Abreu e Lima

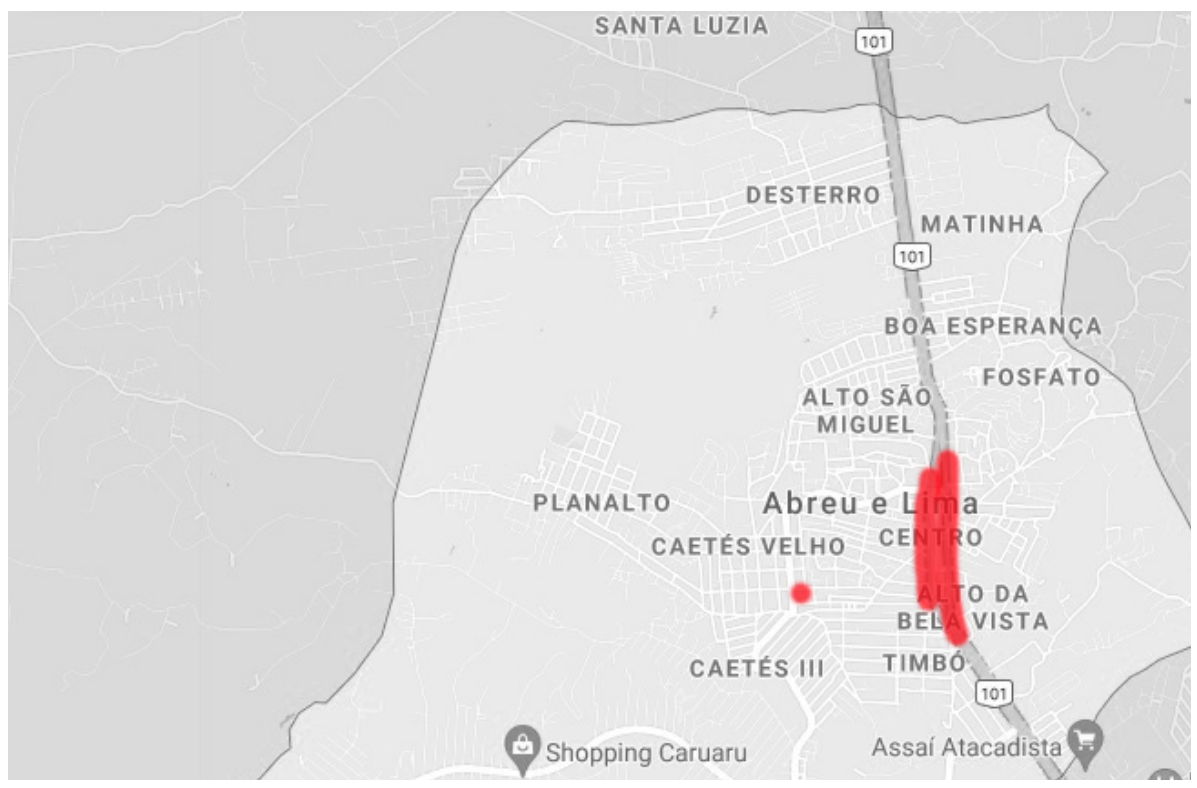

Fonte: Google Maps (modificado), 21 de jul. de 2021

Vejamos alguns aspectos relevantes desses saques com mais atenção. Desde os primeiros saques, que ocorreram a dois caminhões, já é perceptível uma característica recorrente em toda sua ocorrência: a heterogeneidade etária e de gênero dos sujeitos envolvidos na ação coletiva - crianças,

\footnotetext{
${ }^{5}$ Abreu e Lima possui uma população localizada predominantemente na zona urbana (http:// www.abreuelima.pe.gov.br/acidade/historia/) - a única afetada durante os saques. Segundo dados do IBGE (s.d.), a população estimada para 2014 era de 98.201. Um dado relevante para a compreensão do impacto dos saques é que a concentração da atividade econômica, na cidade, está no setor de serviços, sendo um polo comercial de todo o litoral norte pernambucano. Além disso, a desigualdade acentuada é uma característica do município. Isso fica claro em dois dados: o salário médio mensal dos trabalhadores formais era de dois salários-mínimos em 2015, mas a proporção de pessoas ocupadas em relação à população total era de apenas $14.2 \%$. $\mathrm{O}$ outro dado que revela a desigualdade e pobreza da região é que 43,3\% da população tinha, na época, um rendimento mensal de até 1/2 salário-mínimo (IBGE, s.d.).
} 
jovens, mulheres, homens e idosos. Uma entrevistada confirmou essa informação e acrescentou: "por isso que eu tô te dizendo que muita gente que nunca pegou nem um biliro de um vizinho, nem uma fruta, nesse dia se envolveu nisso. Muita gente" (entrevista Priscila, ${ }^{6}$ 03/05/2018). O que remete à questão do lugar da heterogeneidade na hegemonia. Como defendido por Laclau (2013), não há sujeitos puros em mobilizações sociais, pois é em um jogo entre sobredeterminação, contingência e indecidibilidade que os sujeitos constroem as demandas que são heterogêneas ao hegemônico. Em termos específicos ao acontecimento analisado, isso significa que os sujeitos participantes dos saques não se encaixaram na figura do criminoso que constitui o imaginário local. Foi, portanto, um momento em que os moradores da cidade não viram confirmado aquilo que Misse (1999) chama de "sujeição criminal" para lidar com a produção de sujeitos acusáveis. Isso ocorre com o assujeitamento na disseminação de expectativas negativas sobre determinados tipos sociais de incriminados regulares. No Brasil contemporâneo, o jovem negro periférico é, por excelência, o "sujeito criminoso", mas não era exclusivamente ele que estava presente nos saques de Abreu e Lima, pois havia pessoas que não se encaixam nesse mundo à parte que seria o "mundo do crime". Os saqueadores não condizem com uma determinada trajetória de vida que demandaria em algum momento sua incriminação nem têm uma experiência social específica proveniente do contato com outros bandidos. Como reforçou outra descrição coletada em um dos vídeos analisados: "muitos que participaram do vandalismo era gente honesta, trabalhadora e não tinha passagem pela polícia" ("Fantástico conversa com pessoas arrependidas", 2014). Esse é um dos fatores que explica a tamanha surpresa em presenciar os "vizinhos" sem antecedentes criminais realizando os saques.

Entretanto já é evidente que, apesar da diversidade, muitos dos relatos veiculados nos jornais e vídeos e coletados com os entrevistados apontam um traço unificador que é a presença de um ator inesperado: o "vizinho" e o "conhecido". Durante a pesquisa, um representante comercial foi indagado: "nos jornais aparece constantemente a informação de que as pessoas eram conhecidas e fregueses das próprias lojas. Dá para confirmar isso?”. Sua resposta é exemplar daquilo que aparece em muitos outros dados: "isso

\footnotetext{
${ }^{6}$ Dado que os temas tratados são passíveis de criminalização, todos os nomes citados no artigo foram alterados para garantir o anonimato.
} 
é a pura realidade. Porque teve muitos clientes nossos, a gente tem, eu tenho um irmão aqui que tem duas lojas de móveis, a gente viu cliente da gente passando com mercadoria” (entrevista Filipe, 21/08/2018). Por outro lado, foram encontrados também relatos que matizam a participação exclusivamente de conhecidos nos saques, que apontam para o fato de a cidade ser uma grande via de passagem para o litoral norte do estado. Nesse sentido, uma entrevistada afirmou que "houve carros que pararam, que não eram daqui [...]e que aproveitaram a situação [...]. Houve isso, pessoas que nem eram daqui que se juntaram, que veio" (entrevista Marta, 01/10/2018).

Percebe-se o caráter ambíguo dos processos de estabelecimento de identificação antagônica entre os sujeitos, pois, se algumas vezes os abreu-limenses se identificaram com os saqueadores, em outras buscaram estabelecê-los como o outro antagônico. Por mais que tenha sido um processo efêmero, é possível identificar claramente as práticas articulatórias que perpassam esse fenômeno. Durante os saques, os sujeitos construíram identidades que facilitaram tanto a coordenação e realização das ações coletivas de expropriação das lojas quanto a repressão dessas ações. Por um lado, conhecer e se identificar com os "vizinhos"; por outro lado, estabelecer fronteiras entre os saqueadores - o "outro" - e a população abreu-limense - o "nós". Porém, é preciso ressaltar que essas articulações não se fecharam em momentos contraditórios, pois essas identificações constituídas sob "efeitos de fronteira” são instáveis e ambíguas, sempre sujeitas a deslocamentos (Laclau \& Mouffe, 2001).

Com relação à maneira como agiram os sujeitos, foi identificada uma baixa coordenação entre eles, sem a identificação de lideranças - mesmo nos processos criminais. Há, inclusive, alguns depoimentos nos quais os indivíduos falam de decisões individuais. Estariam passando, viram e decidiram participar ou estavam em casa, souberam e foram participar. Esses depoimentos são reforçados por um dos vídeos (Youtube, 2014) que apresenta o saque de um caminhão de bebidas no final da tarde. Nele vemos basicamente as pessoas passando em direção ao veículo e comentando algumas coisas. Uma criança grita: “é cerveja, porra!”. Uma mulher fala: "eu queria pegar uma caixinha”. Ao que uma outra mulher responde: "vai!”. Um homem, possivelmente quem está gravando, resume a cena: “a turma tá com a porra roubando cerveja ali, óa”. Passam crianças, mulheres e homens, alguns usam camisas para esconder o rosto. 
Essa forma de participação remete às teses iniciais da psicologia social que explicavam o comportamento da multidão como decorrentes da sugestibilidade que afetava os indivíduos (Le Bon, 2016). Porém, como explica Laclau (2013), nessas teorias da psicologia social da multidão, a noção de sugestibilidade funcionava como um Deus ex machina de tudo aquilo que não se conseguia explicar e tinha um claro tom demofóbico ${ }^{7}$ porque remetia a um suposto processo de diminuição da inteligência daqueles que participavam da multidão. Há um problema teórico no uso que era feito dessa noção, pois a sugestibilidade era reivindicada como explicação para os processos de mobilização, porém, quando se buscava uma explicação para a própria noção, os argumentos recaíam geralmente em impressões acerca da incapacidade das multidões de agirem racionalmente. A solução de Laclau, para analisarmos os momentos em que supostamente a sugestibilidade estaria em funcionamento, é pensar que esse fenômeno demonstra que os sujeitos compartilham certos aspectos, construídos durante ou existentes antes dos distúrbios, que possibilitam a coordenação entre eles. É, portanto, em diálogo com a ideia de identificação freudiana que Laclau resolve a questão da sugestibilidade, ou seja, através da percepção da importância da partilha de uma "qualidade comum" no laço mútuo entre os membros de um grupo (Freud, 2019).

Entendendo o ocorrido dessa maneira, ter passado, visto e decidido participar vira menos uma ação de alguém que não tem autonomia ou capacidade de reflexão quanto ao ato que está realizando e mais uma ação de alguém que decide participar de uma ação coletiva com aqueles com os quais compartilha algo, com os quais se identifica de alguma forma afinal de contas, como vimos acima, são seus vizinhos e conhecidos que estão saqueando. Assim, a seguinte fala de um dos participantes, "ver a comunidade atacando os comércios, me estimulou" (Passos, 2014, p. 6), torna-se compreensível sem recorrermos a uma acusação baseada na

\footnotetext{
${ }^{7}$ Essa noção busca dar conta do surgimento na política moderna do medo do povo (Aguiar, 2013). Assim como Le Bon, vários pensadores do século XIX se viam frente a uma ambivalência relacionada às múltiplas insurreições da época: se, em alguns momentos, apreciavam a democracia, em outros, tentavam rejeitar os processos revolucionários que estavam em sua origem. Essa ambivalência está relacionada com a duradoura ambiguidade na concepção de povo, pois, como relembra Laclau (2013, p. 134), "o povo pode ser concebido como populus, o corpo de todos os cidadãos, ou como plebs, os desprivilegiados”. O medo do povo é um medo da plebe revoltosa. Assim, a distinção entre plebs e populus se manifesta em um tratamento desigual, pois é a plebe que sofre a demofobia e é ela que seria necessário governar por supostamente ser incapaz de fazer uma política apropriada.
} 
irracionalidade, mas percebendo a existência de aspectos racionais de decisão e de aspectos emocionais de identificação.

Além disso, conjuntamente aos processos de identificação e de articulação, é preciso estar atento às escolhas estratégicas feitas por parte dos que participaram dessas ações coletivas. Acerca desse último ponto, percebeu-se que houve uma seletividade na escolha dos estabelecimentos saqueados: em sua grande maioria eram lojas de médio ou grande porte. A decisão estratégica também se verifica nos pouquíssimos registros de violência contra as pessoas presentes no local - os alvos escolhidos eram basicamente os estabelecimentos. Isso fica claro em um dos vídeos (TV Jornal, 2014) que registra o fato de que, durante os saques, há muita gente parada, observando o que estava acontecendo sem grandes temores de se transformarem em vítimas. Essa característica dos saques deve ser ressaltada para percebermos a importância da tomada de decisões na conformação dos processos políticos, algo ainda mais visível em um momento no qual fica mais perceptível o caráter contingente da hegemonia.

Por fim, identificou-se uma série de antagonismos entre os saqueadores, de um lado, e, do outro, alguns moradores, os donos de lojas, os funcionários das lojas, a mídia, os seguranças privados e as corporações policiais. O que, obviamente, não está apartado dos conflitos cotidianos que permeiam esse evento, principalmente os relativos à desigualdade econômica. Porém, lembremos que o antagonismo, para Laclau e Mouffe (2001), não pode ser delimitado pelo pertencimento a determinadas classes, pois não há um sujeito privilegiado e puro que esteja constituído antes das disputas, sendo os antagonismos - e os sujeitos antagônicos - constituídos no processo de luta. Essa teoria ressalta constantemente o caráter processual e histórico dessas negações. Dessa maneira, torna-se possível compreendermos o fato de haver um antagonismo, mesmo sem necessariamente haver uma distinção de classe entre os funcionários das lojas e os saqueadores. O que obviamente não significa que esse antagonismo não esteja relacionado com coerções provenientes da esfera econômica, pois é plausível levantar a hipótese de que muitos desses funcionários não tiveram muita escolha além de apoiar seus patrões no momento dos saques, por conta das possíveis consequências posteriores.

Se, até aqui, as proposições de Laclau e Mouffe foram esclarecedoras daquilo que ocorreu em Abreu e Lima, é necessário enfatizarmos outras 
questões para a devida compreensão desse momento. É necessário que pensemos esse processo a partir da propriedade e de sua expropriação. Como aponta Devenney $(2011,2020)$, a conformação de ordens hegemônicas tem como fatores importantes a propriedade, o apropriado e o próprio. O autor parte da noção de hegemonia formulada por Laclau e Mouffe (2001), no sentido de uma articulação provisória e parcial das relações sociais entendidas como antagônicas, porém critica seus interlocutores quanto à ênfase que atribuem às identidades políticas nesse processo, preferindo retomar a importância da propriedade para as lutas hegemônicas. Dessa maneira, para além das identificações políticas e das articulações de demandas que Laclau e Mouffe colocam como centrais para a constituição de hegemonias, elas também estariam baseadas em "relações de propriedade e do apropriado, o policiamento dos limites próprios de uma formação social, as ordens logísticas anônimas que colam essas relações e a articulação legal de direitos, liberdades e posições subjetivas” (Devenney, 2020, p. 18).

Como qualquer hegemonia está constantemente reiterando qual a forma apropriada de relação com as propriedades, é possível defender que o momento dos saques significa uma suspensão relativa do cotidiano ${ }^{8}$. Independentemente de seu caráter multifacetado e heterogêneo, está claro que os saques se enquadram no que Devenney chama de "política imprópria”. Esse tipo de performatividade seria a que coloca em questão os limites e os cercamentos típicos da ordem proprietária em que se manifestam. Os saques foram um excesso e, como tal, desestabilizaram o regime usual de propriedade. Porém, se uma "política imprópria" busca questionar aquilo definido politicamente como apropriado pelos regimes de propriedade, não é porque esteja baseada em alguma definição a priori do que a propriedade deva realmente ser - comunal ou coletiva, por exemplo. Em outras palavras, o impróprio é a negação e o questionamento do próprio, e não a afirmação de um outro próprio. Não é, pois, o caso de realizar uma mera inversão moral entre um próprio "mau" e um impróprio "bom", o que nos levaria a uma defesa problemática de que os saques contribuiriam necessariamente para sociabilidades mais igualitárias dado que rompem

\footnotetext{
${ }^{8}$ Acentuar a relatividade dessa suspensão é necessário para evitar cairmos em uma percepção de que esses momentos romperiam completamente com os processos históricos locais, algo que já foi refutado quando foram assinaladas continuidades, como por exemplo as identificações entre "vizinhos" e "conhecidos".
} 
com as desiguais relações presentes em Abreu e Lima. Assim, esse caráter impróprio não implica definições ontológicas, pois, em vez disso, examina como a exclusão faz parte das formas dominantes de ser. A noção coloca, portanto, a importante questão de como as formas apropriadas de ser são aceitas como tal e quais seus efeitos.

Sendo uma manifestação do “impróprio”, podemos pensar que os saques contribuíram para uma crise de hegemonia fugaz em Abreu e Lima. Para Laclau (2013), a crise de hegemonia é o momento em que há uma perda de efetividade dos instrumentos de mediação que conectam as demandas dos distintos sujeitos e o bloco de poder. Como vimos, no momento dos saques houve uma proliferação de pontos de antagonismos, por conta da instabilidade e redefinição das relações sociais. Essa proliferação acarreta uma dificuldade da formação hegemônica em se significar. Foi um momento em que foi difícil o estabelecimento de cadeias unificadas de equivalência e, portanto, o reconhecimento de uma formação hegemônica (Laclau \& Mouffe, 2001). Algo que só pode ocorrer de forma temporária e que se desdobra na criação de novas cadeias de equivalência que buscam reconstituir uma formação hegemônica. Isso se dá num terreno de indecidibilidade e de múltiplos resultados possíveis. Assim, veremos adiante como os processos posteriores aos saques se constituem como restituição do apropriado.

\section{As articulações posteriores aos saques e a reconstituição da hegemonia}

Algumas iniciativas importantes se seguem ao fim da greve e dos saques. Como geralmente ocorre, o Estado buscou a reparação, por meio da punição. Está claro que a resposta estatal priorizou a criminalização em uma abordagem que buscava penalizar individualmente os participantes. Sobre o destino dos saqueadores, após mais de um ano do evento em Pernambuco, 80 pessoas haviam respondido judicialmente por seus atos (Baracho, 2015). Apenas em Abreu e Lima, a depender da fonte consultada, há menções que variam entre oito e quinze pessoas detidas na época. Esse número está muito abaixo do total dos saqueadores, pois os detidos foram apenas aqueles autuados em flagrante ao serem encontrados com mercadorias saqueadas. É interessante perceber que, assim como os próprios saqueadores eram 
“conhecidos, familiares e vizinhos”, também muitas das delações nos dias posteriores vinham de pessoas próximas aos detidos. Isso reforça que não houve apenas o apoio e a identificação da população com os atos, mas também uma ruptura nas relações cotidianas entre os sujeitos locais.

A tipificação criminal a que foram submetidos os indiciados variou entre furto (de um a quatro anos de reclusão), furto qualificado (dois a oito anos), roubo (quatro a 10 anos), receptação (um a quatro anos) e receptação qualificada (três a oito anos). Ao olharmos para a história dos saques no Nordeste brasileiro, é possível perceber que houve uma mudança importante na forma de criminalizá-los. Nos que ocorreram na metade do século XX, a interpretação jurídica mais comum é a de que eram “crimes multitudinários”. Essa forma de tipificação apontava para o caráter coletivo da ação e para um tipo de roubo que tinha características atenuantes, pois estava relacionado com um problema social. A ordem cotidiana relacionava os saques à fome e, assim, eram tanto um problema de polícia quanto de assistência aos necessitados (Neves, 2000). Porém, o caso de Abreu e Lima, ilustra como atualmente é incomum que os saques, no Brasil, sejam interpretados como crime multitudinário, sendo a categoria jurídica mobilizada mais usualmente a de roubo. O Estado se esforça para individualizar a criminalização e para retirar o estatuto político dos saques - eles agora são um problema quase que exclusivamente policial.

Para além do Estado, outra iniciativa posterior aos saques a ser pontuada é a devolução das mercadorias saqueadas. Já no dia 16 de maio, as pessoas começaram a devolver mercadorias variadas: geladeiras, fogões, equipamentos eletroeletrônicos, bebidas alcoólicas... É perceptível uma busca em reestabelecer o cotidiano, pois "as pessoas comuns" que participaram dos saques pretendiam retomar suas atividades sem serem punidas. Nesse momento, os que devolviam fizeram muitas menções a sentimentos como vergonha, arrependimento, constrangimento e alívio. Um homem de 46 anos afirmou: "vim devolver um freezer que peguei numa loja quarta-feira passada. Estou sem dormir desde esse dia, arrependido e com muita vergonha" ("Abreu e Lima refém”, 2014, p. 2). Em outro relato vemos uma dona de casa que perdeu o sono e o apetite. Ela afirmava ter crises de choro frequentes desde que participou dos saques ("Fantástico conversa com pessoas arrependidas", 2014). 
Entre as pessoas que foram até a delegacia fazer a devolução, sabe-se que muitas foram incentivadas ou levadas por seus familiares para realizarem esse ato. Quando um dos participantes foi questionado sobre o motivo da devolução, ele afirmou ter feito por sua família. "Tenho a minha filha, pensei em que tipo de exemplo eu estava dando a ela. Por esse motivo, decidi trazer de volta. Meus pais não me ensinaram isso" (Passos, 2014, p. 1). Outra estratégia utilizada foi largar as mercadorias em locais públicos para evitar serem identificados como saqueadores. Há muitos relatos de produtos deixados nas ruas - com alguns abandonados até mesmo no cemitério local. Algo que é plausível relacionar com os sentimentos de vergonha e com o medo de responsabilização pela participação.

Ainda a esse respeito, para além dos sentimentos de vergonha e culpa e do incentivo das famílias, também é importante pensarmos no papel da religião e da mídia nesse processo de devolução. Foi descoberto, no trabalho de campo, que a Assembleia de Deus realizou vários cultos nos dias seguintes com o propósito de "conscientizar" as pessoas com relação aos atos praticados e da importância de devolverem os produtos saqueados. Ademais, muitas foram as matérias veiculadas nos dias seguintes que mostraram o delegado de Abreu e Lima fazendo um apelo para o arrependimento dos saqueadores. Nessas matérias há repetidas promessas de que os que fossem devolver na delegacia não seriam autuados em flagrante. Além disso, um dos entrevistados ressaltou que na cidade houve muita conversa acerca de uma construção midiática: as "mães de Abreu e Lima”. Pessoas próximas ao prefeito pensaram em fazer um monumento para esse personagem salvador que teria virado um símbolo ao ajudar a restituição da ordem na cidade ao levar os filhos para devolverem as mercadorias - algo que nunca foi concretizado.

Articuladas com esses processos, ocorreram duas relevantes iniciativas para reestabelecer moralmente a imagem da cidade. A primeira ocorreu no dia 20 de maio, quando cerca de 100 jovens saíram da Igreja Matriz de São José para orar pelas ruas de Abreu e Lima. Organizada pelo grupo católico Espírito Jovem, eles enfeitaram as lojas saqueadas com 2.500 corações de papel, nos quais havia frases bíblicas e pedidos de paz. Dentre as mensagens, havia o nome da iniciativa "\#aquibateumcoração" e outras como: "Deus é fiel”, “Obrigado senhor”, “\#amigos”. Segundo os participantes, o objetivo 
era mostrar que nem todos os habitantes do local concordavam com "os recentes saques e arrastões que tomaram conta das ruas durante a greve da Polícia Militar” (“Corações para selar a paz”, 2014).

A segunda iniciativa foi um ato de maior proporção realizado no domingo, 25 de maio, na Praça São José no centro da cidade. Esse ato foi organizado conjuntamente pela Câmara dos Dirigentes Lojistas, a prefeitura, a câmara dos vereadores, associações de moradores e diversas esferas da sociedade civil organizada. A proposta era “"mostrar que os abreu-limenses não concordam com o vandalismo, com os saques. Somos um povo tranquilo', disse Elisabete Dino, diretora de uma escola da rede estadual e uma das organizadoras do ato" ("Uma caminhada pela cidadania”, 2014, p. 12). O movimento \#nossacidadedevolta fez camisas da campanha, vendidas por $\mathrm{R} \$ 10,00$, e uma página no Facebook. Dois dias antes do ato, a prefeitura emitiu uma declaração afirmando que

\begin{abstract}
A Prefeitura de Abreu e Lima, no Grande Recife, aderiu ao movimento que quer virar a triste página da história recente da cidade. Os atos de vandalismo e saques que ocorreram nos dias 14 e 15 deste mês, durante a greve dos policiais militares, abalaram a vida dos moradores, mas não o amor que sentem pela cidade. [...] A prefeitura apoia o evento [...] e lança uma campanha de autoestima: "Sou Abreu e Lima, Sou do Bem”, numa clara confirmação que foi uma minoria (e até de fora) os que participaram dos atos de vandalismo e saques.
\end{abstract}

No domingo, cerca de mil pessoas foram vestidas de branco às ruas da cidade. Falavam em recuperar a imagem da cidade e na não representatividade dos que saquearam. Além dos organizadores já citados, o ato contou com a participação de dez escolas públicas e privadas, igrejas católica e evangélicas, comerciantes, movimentos sociais, e ainda da Ordem dos Advogados do Brasil (OAB) e do Ministério Público de Pernambuco (MPPE). O ato começou com uma apresentação da banda marcial de uma escola local e depois aconteceu a leitura do manifesto "Nossa cidade de volta”, que comparava a iniciativa dos abreu-limenses ao realizado em Londres depois das revoltas de 2011. O manifesto defendia que a devolução dos produtos saqueados não bastava. Um trecho dizia: "essa ação é pautada pela reivindicação da garantia de direitos econômicos, sociais e culturais. Acreditamos, portanto, que é possível integrar iniciativas no campo da 
educação, cultura e segurança cidadã, sem criminalizar a pobreza, que ainda atinge a maioria da população" (“Uma caminhada pela cidadania”, 2014, p. 12). Depois da leitura do manifesto, ocorreu um rápido culto ecumênico, uma caminhada pelos dois principais corredores de comércio do centro da cidade e, por fim, uma roda de ciranda. Durante a manifestação, a secretária de Educação anunciou que implantaria um programa nas escolas sobre a importância de cultivar a cidadania.

Nas declarações recolhidas nesse domingo, vemos que o processo de estigmatização dos moradores da cidade já havia começado e que eles tentavam reagir a isso. Havia claramente a tentativa de estabelecimento de fronteiras discursivas entre os cidadãos abreu-limenses e os saqueadores: "uma minoria que participou dos atos de vandalismo e dos saques não representa todo um município. Ainda mais porque somos considerados a cidade mais evangelizada do Brasil, inclusive o prefeito é pastor. Isso não condiz com o nosso comportamento", afirmou Marcos Aurélio, o vicepresidente da Câmara de Vereadores do município ("Uma caminhada pela cidadania”, 2014, p. 12). O prefeito Pastor Marcos disse: “aqui tem gente decente. Soube que muitos sequer eram daqui. Algumas pessoas de Abreu e Lima viram e se empolgaram. O povo daqui não é marginal” ("Em busca da redenção", 2014, p. 4). Outra fala reforça esse processo ao dizer que o evento seria "uma tentativa de limpar a imagem da cidade" ("Uma caminhada pela cidadania”, 2014, p. 12).

É interessante notar que a disputa surgida no momento posterior aos saques, sobre quem seriam os verdadeiros abreu-limenses, é uma disputa pela constituição de qual parte do povo se identifica com o todo (Laclau, 2013), ou seja, qual discurso articula em torno de si seus equivalentes. Para aqueles que distribuíram corações nas ruas e se reuniram no domingo, essa parte não poderia ser os saqueadores. A busca era por construir uma cadeia de equivalências que tornasse hegemônica a ordem por eles considerada a legítima, ordem que seria a negação do ocorrido nos saques. Ainda que os discursos apresentem diferenças importantes - como se percebe na discrepância entre as preocupações sociais do manifesto veiculado e as declarações morais do discurso religioso - vemos a articulação desses distintos sujeitos que nem sempre coadunam. Naquele momento, eles buscavam um consenso provisório e parcial que garantisse a supressão 
do que consideraram ser uma anomia. Como aponta Laclau (2013), ao pensar nas cadeias de equivalência, a definição de fronteiras é constituinte do estabelecimento de uma hegemonia. Sendo o social uma relação de múltiplas diferenças que necessitam de um externo ao qual essas diferenças igualmente se opõem para criar uma equivalência e para que a totalização ocorra - ainda que de maneira precária e provisória - podemos pensar o quanto os saques se constituíram como esse externo antagonizado para a reconstituição de uma hegemonia em Abreu e Lima.

Por fim, retomemos, de Devenney (2011, 2020), a centralidade da propriedade, do apropriado e do próprio para a constituição e manutenção das ordens hegemônicas. Tenhamos em mente que a propriedade é entendida como contingente e política. É sempre um processo de disputa, pois qualquer tipo de propriedade requer justificações que são alvo de contestações. Durantes os saques, a forma costumeira e apropriada de relação com as mercadorias - mediada pelo dinheiro - foi questionada. Assim, a contingência revelada pela impropriedade dos saques demonstra o caráter histórico das propriedades. Como já exposto no tópico anterior, não cabe aqui a defesa de uma forma apropriada de propriedade, pois essa é sempre fruto de relações sociopolíticas contingentes: "se o social não é uma estrutura fechada, definida por uma essência subjacente, então não há propriedade original, nenhuma estrutura original que mais tarde adquira forma jurídica. Pelo contrário, a propriedade é performativamente refeita em contextos específicos” (Devenney, 2020, p. 17).

Dessa maneira, a propriedade não é entendida como um objeto ou uma coisa possuída legalmente por uma pessoa, mas como uma série de relações sobredeterminadas - que incluem articulações políticas, econômicas e legais - que demarcam e ordenam o espaço, o tempo e a subjetividade através de cercamentos. Estamos, portanto, necessariamente lidando com processos de formação de hegemonias, em meio aos quais a propriedade estabelece uma série de relações e contribui para definir aquilo que é apropriado e o que é inapropriado. Como a propriedade e a determinação daquilo que seria “próprio" ao ser estão intimamente articuladas, há um processo de subjetivação em jogo que vai além das identidades e se refere a relações de inclusão e exclusão dos sujeitos. Assim, as propriedades, em qualquer 
maneira como se manifestem, dependem necessariamente de um cercamento, do estabelecimento de limites entre o que está excluído e o que está incluído.

O caso de Abreu e Lima deixa claro que há uma articulação entre os aspectos mais estritamente econômicos e a definição de formas apropriadas de comportamento e subjetividade. Os "vizinhos" e "conhecidos" que saquearam e ultrapassaram os limites da maneira apropriada de relação entre si e com as mercadorias expuseram aspectos importantes de conformação da hegemonia no local. Esse processo de totalização contingente não pode prescindir da propriedade. Por isso, concomitantemente a esses atos, alguns desses sujeitos estiveram se articulando em torno de pautas econômicas de fortalecimento do comércio local. No dia 21 de maio, os comerciantes se reuniram para organizar as reivindicações que fariam ao governo do estado. Uma das principais demandas era a devolução e o parcelamento dos impostos referentes aos produtos saqueados. Eles foram recebidos pelos deputados estaduais e pelo governador para discutir formas de ajudar o município após os saques. Enfatizaram o desejo de desoneração fiscal, porém não foram atendidos pelo governo estadual. Apesar disso, como pontuou um dos entrevistados alguns anos depois: "você pode ver que aos poucos, novas lojas e novos mercados vão se abrindo, onde antes existiam aqueles que foram fechados por conta dos saques que é o caso do Arco Íris” (entrevista João, 27/11/2017). Ou seja, apesar de não ver atendidas suas demandas mais imediatas de reparação financeira, o comércio também se recuperou rapidamente em Abreu e Lima. Dessa maneira, percebemos a hegemonia sendo reestabelecida através da articulação entre uma determinada forma de distribuição de mercadorias e de definição das formas apropriadas de se portar na cidade, formas que evidentemente excluem os saques que, desde então, não se repetiram no local.

A reconstituição do apropriado se deu na articulação de processos bastante diversos: a devolução de mercadorias e as influências exercidas pelas famílias, igrejas e mídia, as demandas feitas pelo comércio local, as campanhas de "revalorização" da cidade, a estigmatização dos moradores e os sentimentos que ainda mediam a relação com o acontecimento. A propriedade como relação desigual e violenta de cercamento, que ordena o espaço e o tempo, voltou, dessa maneira, às suas formas mais usuais e com ela se retomava o que é apropriado para a hegemonia local. 


\section{Considerações finais}

Em um determinado momento, Hobsbawm (1970) utilizou o termo prépolítico para caracterizar as revoltas sem projeto político e sem organização perceptíveis. Isso revela a adoção de um determinado conceito de política, que define o que seriam as relações de poder e as formas legítimas de manifestação das vontades coletivas. Por trás da acusação de pré-político, está uma concepção de política que a resume a estruturas estáveis de organização dos sujeitos coletivos, ao relacionado estritamente ao Estado e à necessidade de uma estrutura de liderança. Nessa concepção, aquilo que não preenche esses critérios, é visto como selvageria. A análise aqui desenvolvida demonstra o problema de concepções desse tipo. Aqui, os saques foram compreendidos como um fenômeno político que torna visíveis antagonismos cotidianos e cria outros. Concordamos, portanto, com a defesa de Mouffe (2005) de não resumir o político à política, pois o político seria a dimensão do antagonismo constituinte ao social e a política seria o conjunto de práticas e de instituições por meio do qual esse antagonismo é gerido.

Lembremos também que Laclau (2013) defende a primazia do político sobre o social. Para o autor, nosso mundo social está instituído politicamente e tudo pode ser visto e analisado a partir do político. Como o político é ontologicamente antagônico, estamos diante de um mundo conflitivo e da negação. Assim, o social e o político não são entendidos como dois momentos apartados, mas dois momentos distintos do político, pois todo social foi, em algum momento, instituído politicamente. O social seria o âmbito das práticas sedimentadas e o político o da instituição ou reativação dessas práticas (Laclau, 2013). Dessa maneira, os saques podem ser vistos como um exemplo paradigmático do político por serem uma expressão nua do antagonismo que nem sempre se mostra aos olhos cotidianos.

Além disso, sendo uma ação política que congrega a heterogeneidade social, o saque não controla quais demandas incorpora e articula. Não é uma deficiência dos saques em Abreu e Lima serem ambíguos, isso é constitutivo deles enquanto manifestação daquilo que escapa ao hegemônico. Portanto, concebendo-os politicamente, interessa menos condenar as suas indefinições ou o fato de não terem um vetor político unidirecional e mais realizar aquilo que foi proposto como objetivo dessa pesquisa: verificar como eles se manifestaram em uma luta hegemônica e como depois se sedimentaram em um social renovado. 


\section{Referências}

Abreu e Lima refém do medo e de boatos. (2014, 20 maio). Jornal do Commercio (p. 2).

Aguiar, Thais. (2013). Uma genealogia de princípios de demofilia em concepções utópicas de democratização (Tese de doutorado, Universidade do Estado do Rio de Janeiro). https://www.bdtd.uerj. br:8443/handle/1/12413

Althusser, Louis. (2015). Por Marx. Editora da Unicamp.

Baracho, Maira. (2015, 13 maio). Um ano depois, Abreu e Lima exorciza o trauma da greve da PM. Diario de Pernambuco. https://www. diariodepernambuco.com.br/noticia/vidaurbana/2015/05/um-anodepois-abreu-e-lima-ainda-exorciza-o-trauma-da-greve-da-pm.html

Benzaquen, Guilherme F. (2020). Os saques em Abreu e Lima na greve da Polícia Militar de Pernambuco em 2014 (Tese de doutorado, Universidade Federal de Pernambuco). https://repositorio.ufpe.br/ handle/123456789/38086

Corações para selar a paz. (2014, 21 maio). Folha de Pernambuco (p. 5).

Devenney, Mark. (2011). Property, propriety and democracy. Studies in Social Justice, 5(2), 149-165. http://dx.doi.org/10.26522/ssj.v5i2.984

Devenney, Mark. (2020). Towards an improper politics. Edinburgh Press.

Em busca da redenção. (2014, 26 maio). Diario de Pernambuco (p. 4).

Fantástico conversa com pessoas arrependidas de saque em PE. (2014, 25 maio). G1. http://g1.globo.com/fantastico/noticia/2014/05/saqueadoresarrependidos-devem-ter-penas-mais-brandas-diz-delegado.html

Flick, Uwe. (2009). Qualidade na pesquisa qualitativa. Artmed.

Freud, Sigmund. (2019). A interpretação dos sonhos. Companhia das Letras.

Gramsci, Antonio. (2002). Cadernos do cárcere (Vol. 5). Civilização Brasileira.

Hobsbawm, Eric. (1970). Rebeldes primitivos: estudo sobre as formas arcaicas dos movimentos sociais nos séculos XIX e XX. Rio de Janeiro: Zahar.

IBGE. (s.d.). Cidades/Pernambuco/Abreu e Lima. https://cidades.ibge.gov.br/ brasil/pe/abreu-e-lima

Le Bon, Gustave. (2016). Psicologia das multidões. WC Martins Fontes. 
Laclau, Ernesto. (2013). A razão populista. São Paulo: Três Estrelas.

Laclau, Ernesto. (1990). New reflections on the revolution of our time. Verso.

Laclau, Ernesto, \& Mouffe, Chantal. (2001). Hegemony and socialist strategy: towards a radical democratic politics. Verso.

Misse, Michel. (1999). Malandros, marginais e vagabundos: a acumulação social da violência no Rio de Janeiro (Tese de doutorado, Universidade Federal do Rio de Janeiro). https://minerva.ufrj.br/ $\underline{\mathrm{F} / \text { ?func }=\text { direct\&doc number }=000467199 \& \text { local base }=\mathrm{UFR} 01}$

Mouffe, Chantal. (2005). On the political. Abingdon: Routledge.

Mutzenberg, Remo. (2003). Identidades e movimentos sociais numa sociedade indomável. Revista Política e Trabalho, 19, p. 39-58.

Neves, Frederico. (2000). A multidão e a história: saques e outras ações de massas no Ceará. Relume Dumará.

Passos, Rodrigo. (2014). O arrependimento não tardou. Folha de Pernambuco, Recife, p. 1, 17 mai. 2014.

Youtube. (2014). Protesto em Abreu e Lima teve saque de tudos e tudos! [Arquivo de vídeo]. https://www.youtube.com/watch?v=mcV-cdy0ajs

TV Jornal (2014). Abreu e Lima faz aniversário e tem lojas saqueadas durante greve da PM [Arquivo de vídeo]. https://www.youtube.com/ watch?v=y8afoTXzX0I

Uma caminhada pela cidadania. (2014, 26 maio). Jornal do Commercio (p. 12).

Submetido em: 21 jun. 2020.

Aprovado em: 19 jul 2021.

\section{(cc) $\mathrm{BY}$}

Licenciado sob uma Licença Creative Commons Attribution 4.0 